\title{
MODIFIED JOHNSON-COOK PLASTICITY MODEL WITH DAMAGE EVOLUTION: APPLICATION TO TURNING SIMULATION OF 2XXX ALUMINIUM ALLOY
}

\author{
H. Ijaz* M. Zain-ul-abdein W. Saleem \\ Mechanical Engineering Department \\ University of Jeddah \\ Jeddah, Saudi Arabia
}

M. Asad

Mechanical Engineering Department College of Engineering

Prince Mohammad Bin Fahd University AlKhobar, Saudi Arabia

T. Mabrouki

Mechanical Engineering Department

University of Tunis El Manar, ENIT

Tunis, Tunisia

\begin{abstract}
Mechanical properties of the metals and their alloys are influenced by the material grain size at microscale. In the present study, the Johnson-Cook (JC) material model is modified to incorporate the effect of material's grain size along with the plasticity coupled damage model. 2D finite element (FE) simulations of turning process of an aerospace grade aluminium alloy 2024 (AA2024) were performed with different grain sizes using a commercial FE software, ABAQUS/Explicit. FE simulation results were compared with the published experimental data on turning process of AA2024. The proposed modified JC material model successfully simulated the increase in cutting force as a function of grain size refinement.
\end{abstract}

Keywords: Finite element analysis, Modified Johnson-Cook model, Grain size, Turning process.

\section{INTRODUCTION}

Aluminum alloy 2024 (AA2024) has a wide range of applications in the aerospace industry due to its low density and excellent mechanical properties. This alloy may undergo different cutting processes like, turning, milling, etc. before reaching a finished product stage. Moreover, it may require several heat treatment processes for various applications. These processes alter the grain structure and size that result in significant changes in the mechanical properties. In their work, Hall [1] and Petch [2] described the yield strength dependency upon the grain size. Owing to the enhanced material properties, the cutting tools also experience different magnitude of cutting forces, which ultimately affect the tool's wear and service life.

Finite element (FE) analysis can be applied accurately to predict the cutting force and the chip formation morphology by substituting the expensive and real time machining prototypes (Vivekananda et al., Stalin John et al., Agmell et al., Yin et al., Wu et al. [3-7]). In recent times, the trends in modelling and analysis have shifted from macro to micro regimes so as to simulate the finest possible details of the real time problems. The works of Ijaz et al. [8], Liu et al. [9], Xinmin et al. [10] and Subbiah and Melkote [11] are mainly focused upon the micro-scale modelling and the FE analysis of the machining processes. Cracks and cutting processes can be modeled by using the fracture mechanics (Meng and Wang [12]), or the damage mechanics (Ijaz et al. [13]) based theories. Johnson-Cook (JC) [14] proposed a comprehensive material model based on the plasticity and damage evolution laws. Many authors like Zhang et al. [15], Shrot et al. [16], Asad [17] and Mabrouki et al. [18] have

*Corresponding author (hassan605@yahoo.com) 


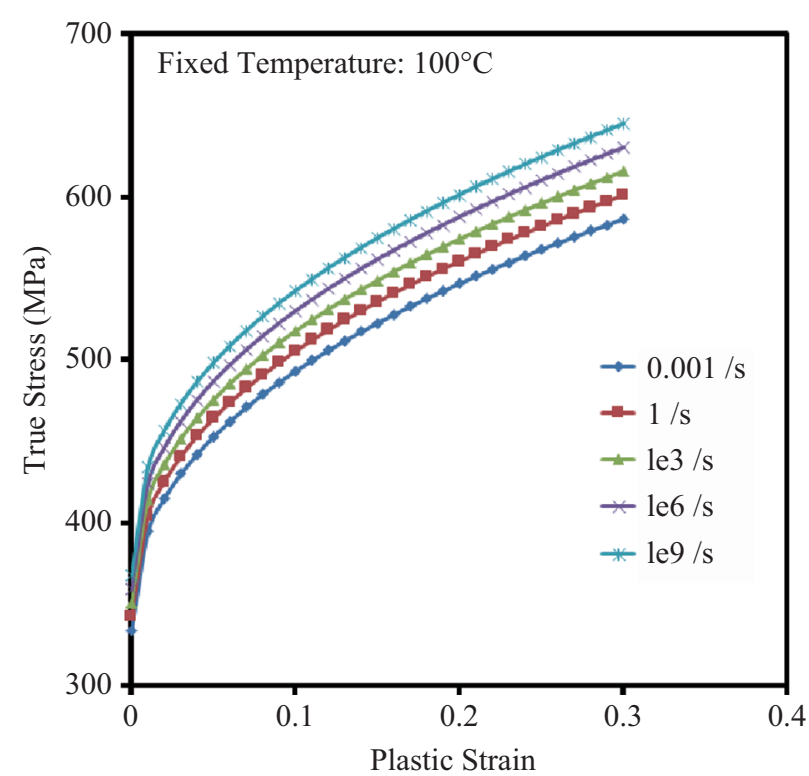

Fig. 1 True stress-strain behavior of AA2024 at constant temperature.

employed the JC model to successfully simulate the turning process and the chip formation of the metallic materials. Hence, the FE cutting simulations may assist in the selection of a proper cutting tool with respect to its service life by predicting the cutting forces.

Generally, the heat treatment processes improve the mechanical properties by re-crystallizing the atomic structure and varying the grain size. The JC-model, though reasonably good at macro scale, does not account for changes in the grain size. In this context, a modified JC material model is being proposed here that also includes the effect of grain size. FE analysis of AA2024 turning process has been performed based on the proposed material model. The simulation results have been compared with the published experimental data for the cutting forces.

This paper is organized as follows:

In section 2, classical JC material model with damage evolution law is presented. Yield strength as a function of material's grain size using Hall-Petch relation is described. Modified JC material model that incorporates the grain size effect is discussed in section 3. Experimental results on turning process AA2024 are detailed in section 4. FE modeling and analysis are presented in section 5. Results are reported and discussed in section 6. Finally, concluding remarks are made in section 7.

\section{PLASTICITY AND DAMAGE COUPLED JOHNSON-COOK MATERIAL MODEL}

The machining process of aluminium alloy can be simulated by using the JC material model [14] defined as follows:

$$
\bar{\sigma}=\underbrace{\left(\sigma_{y}+B \bar{\varepsilon}^{n}\right)}_{\text {Plastic term }} \underbrace{\left[1+C \ln \left(\frac{\dot{\bar{\varepsilon}}}{\dot{\bar{\varepsilon}_{0}}}\right)\right]}_{\text {Viscosity term }} \underbrace{\left[1-\left(\frac{T-T_{\text {room }}}{T_{\text {melt }}-T_{\text {room }}}\right)^{m}\right]}_{\text {Softening term }}
$$

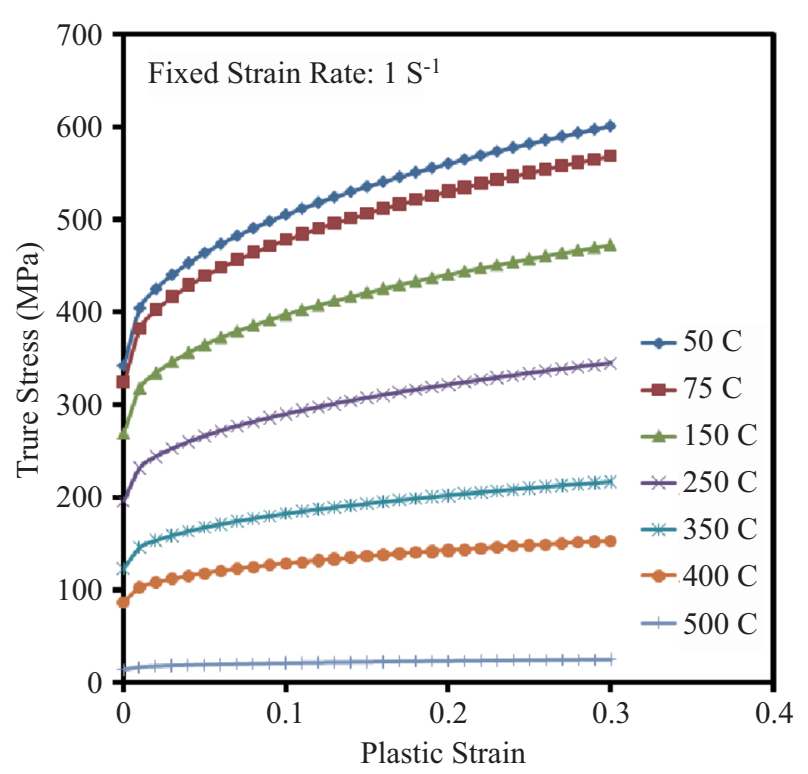

Fig. 2 True stress-strain behavior of AA2024 at constant strain rate.

Figures 1 and 2 show the true stress-strain behavior at constant temperature and constant strain rate, respectively, for AA2024 using Eq. (1). The JC model inherently takes care of plasticity effects as a function of yield strength, viscosity response due to different strain rates and softening effects caused by the temperature.

If $\bar{\varepsilon}_{0 i}$ is the plastic strain at damage initiation, then [14]:

$$
\begin{gathered}
\bar{\varepsilon}_{0 i}=\left[D_{1}+D_{2} \exp \left(D_{3} \frac{P}{\bar{\sigma}}\right)\right]\left[1+D_{4} \ln \left(\frac{\dot{\bar{\varepsilon}}}{\frac{\dot{\bar{\varepsilon}}}{\bar{\varepsilon}_{0}}}\right)\right] \\
{\left[1+D_{5}\left(\frac{T-T_{\text {room }}}{T_{\text {melt }}-T_{\text {room }}}\right)\right]}
\end{gathered}
$$

where, the damage constants $\left(D_{1} \sim D_{5}\right)$ are determined experimentally [12]. Different JC material parameters for AA2024 are given in Table 1.

Table 1 Johnson-Cook material parameters for AA2024 [17]

\begin{tabular}{|c|c|c|c|c|c|c|c|c|c|}
\hline $\begin{array}{c}\boldsymbol{\sigma}_{\boldsymbol{y}} \\
(\mathbf{M P a})\end{array}$ & $\begin{array}{c}\boldsymbol{B} \\
(\mathbf{M P a})\end{array}$ & $\boldsymbol{n}$ & $\boldsymbol{C}$ & $\boldsymbol{m}$ & $\boldsymbol{D}_{\mathbf{1}}$ & $\boldsymbol{D}_{\mathbf{2}}$ & $\boldsymbol{D}_{\mathbf{3}}$ & $\boldsymbol{D}_{\mathbf{4}}$ & $\boldsymbol{D}_{\mathbf{5}}$ \\
\hline 352 & 440 & 0.42 & 0.0083 & 1 & 0.13 & 0.13 & -1.5 & 0.011 & 0 \\
\hline
\end{tabular}

Damage is initiated when a scalar parameter $\omega$ exceeds 1 and this parameter can be written as (Han et al. [19]):

$$
\omega=\frac{\sum \Delta \bar{\varepsilon}}{\bar{\varepsilon}_{0 i}}
$$

If $G_{f}$ is the fracture energy required for the creation 

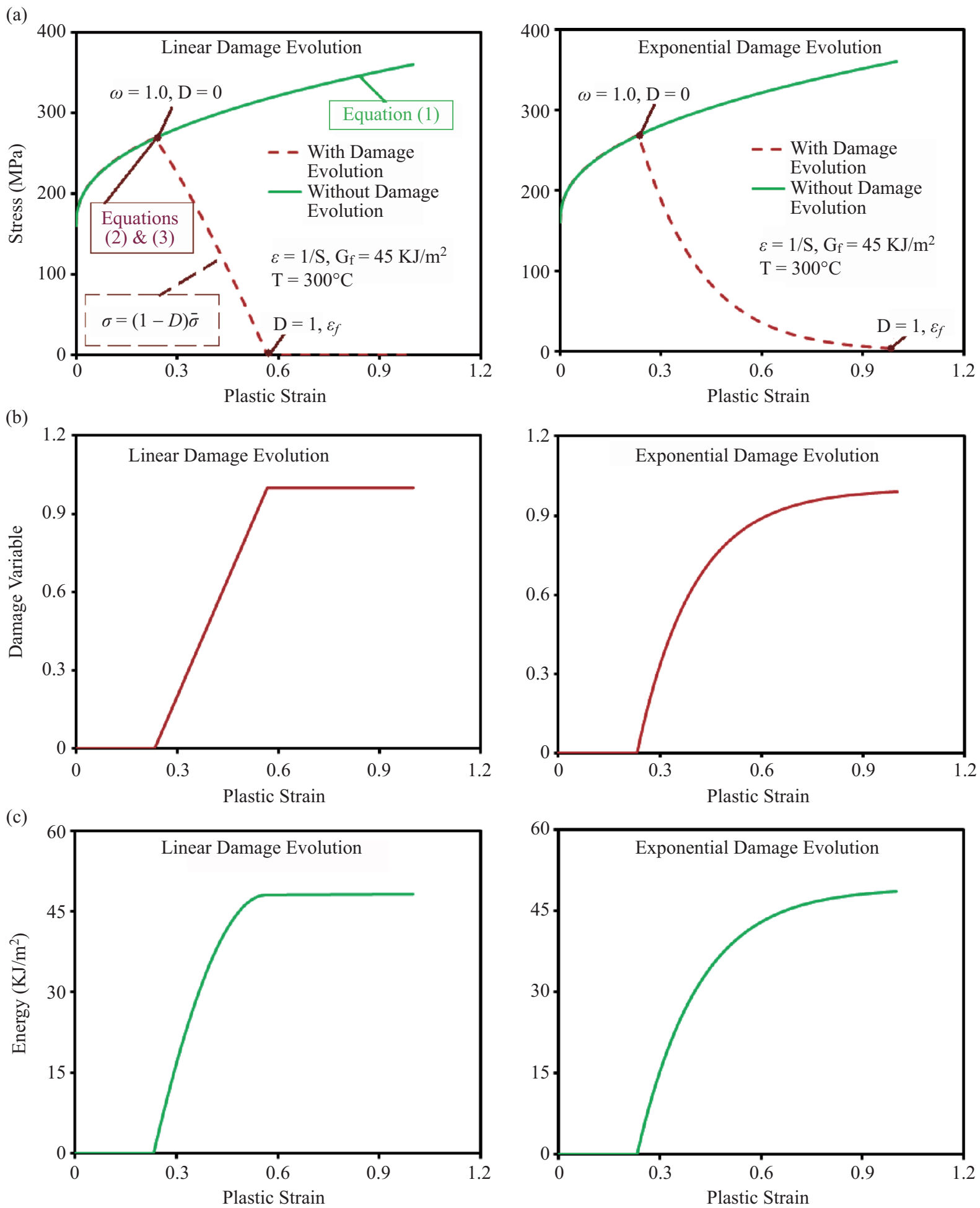

Fig. 3 Uni-axial stress-strain response of Johnson-Cook plasticity and damage model.

and propagation of a crack, then following relation can be written according to Hillerborg et al. criteria [20]:

$$
G_{f}=\int_{0}^{\bar{u}_{f}} \sigma_{y} d \bar{u}
$$

In the above equation, the equivalent plastic displacement at failure $\left(\bar{u}_{f}\right)$ can be calculated by using following relation, Shi and Liu [21]:

$$
\bar{u}_{f}=\frac{2 G_{f}}{\sigma_{Y}}
$$

Now the mode-I and mode-II fracture energy an be found from the experiments using following relation, Vivekananda et al. [3]:

$$
\left(G_{f}\right)_{I, I I}=\left(\frac{1-v^{2}}{E}\right)\left(K_{C}^{2}\right)_{I, I I}
$$


Once the damage is initiated under the given loading conditions, the linear or exponential laws can be employed for the damage evolution in the ductile materials. The equivalent plastic displacement $\left(\bar{u}_{f}\right)$ and the fracture energy $\left(G_{f}\right)$ are related to the damage variable $(D)$ with following relations, Asad [17]:

$$
\begin{gathered}
D=\frac{\bar{u}}{\bar{u}_{f}} \\
D=1-\exp \left(-\int_{0}^{\bar{u}} \frac{\bar{\sigma}}{G_{f}} d \bar{u}\right)
\end{gathered}
$$

The uni-axial stress strain response of JC model for linear and exponential damage evolution law is shown in Fig. 3. Now, the resultant stress with damage evolution is calculated using the classical equation, $\sigma=(1-D) \bar{\sigma}$.

Figure 3(a) shows the stress-strain behavior when the damage is initiated and parameter $\omega$ approaches a value 1. Note that at this instant the damage variable $D$ is initiated with a value 0 and then it evolves either linearly or exponentially. The fracture process is completed when the variable $D$ approaches a value of 1 and the stress reduces to zero as the material can no longer withstand the applied loading, see Fig. 3(a). $\quad \varepsilon_{f}$ and $\bar{u}_{f}$ are the corresponding failure strain and displacement, respectively, at the time of complete fracture i.e. $D=1$. The linear and exponential evolutions of damage variable and fracture energy are shown in Figs. 3(b) and 3(c), respectively.

\section{GRAIN SIZE EFFECT AND MODIFIED JOHNSON-COOK MODEL}

The material's yield strength $\left(\sigma_{y}\right)$ is related to the grain size $(d)$ according to the Hall-Petch equation [1-2]:

$$
\sigma_{y}=\sigma_{o}+K_{H P} \cdot d^{-1 / 2}
$$

The yield strength of the pure Alminium alloy is 12.4 $\mathrm{MPa}$ with a grain size of $0.035 \mathrm{~mm}$, Hansen [22], and the friction stress value is $10 \mathrm{MPa}$ (Simar et al. [23] and Deschamps and Brechet [24]). Now the major contribution in the increase in yield strength of AA2024 $\left(\sigma_{y}=\right.$ $352 \mathrm{MPa}$ [17]) is due to the alloying addition and heat treatment process. Assuming a constant value of grain size, eq. (9) can be used to calculate $K_{H P}$ as $63 \mathrm{MPa}^{\mathrm{mm}}{ }^{1 / 2}$, Zain-ul-abdein and Nélias [25].

In order to accommodate the grain size effect on the yield strength, the term $\sigma_{y}$ in the classical JC eq. (1) can now be replaced using the relation (9) as:

$$
\begin{aligned}
\bar{\sigma} & =\underbrace{\left(\sigma_{o}+K_{H P} \cdot d^{-1 / 2}+B \bar{\varepsilon}^{n}\right)}_{\begin{array}{c}
\text { Grain-size depenent } \\
\text { strain hardening term }
\end{array}} \underbrace{\left[1+C \ln \left(\frac{\dot{\bar{\varepsilon}}}{\dot{\bar{\varepsilon}}_{0}}\right)\right]}_{\text {Viscosity term }} \\
& \underbrace{\left.1-\left(\frac{T-T_{\text {room }}}{T_{\text {melt }}-T_{\text {room }}}\right)^{m}\right]}_{\text {Softening term }}
\end{aligned}
$$

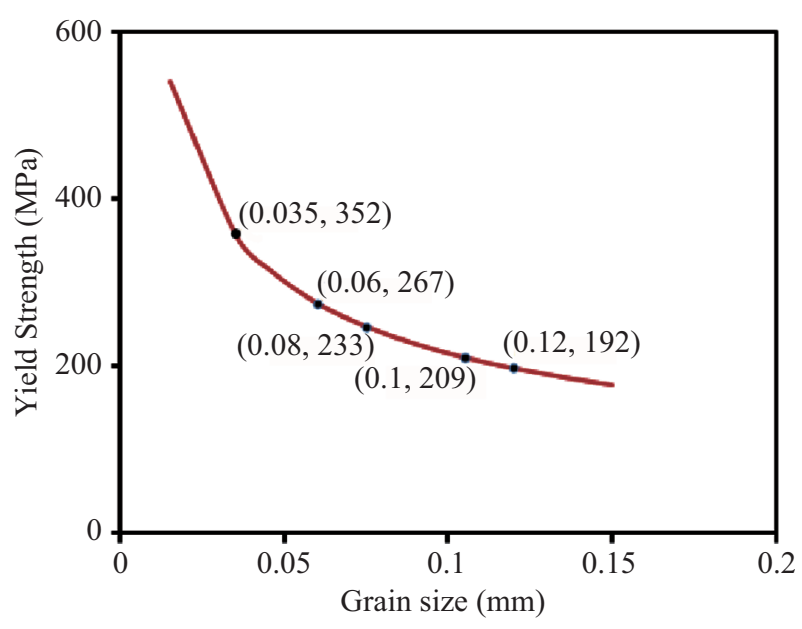

Fig. 4 Yield strength as a function of grain size.

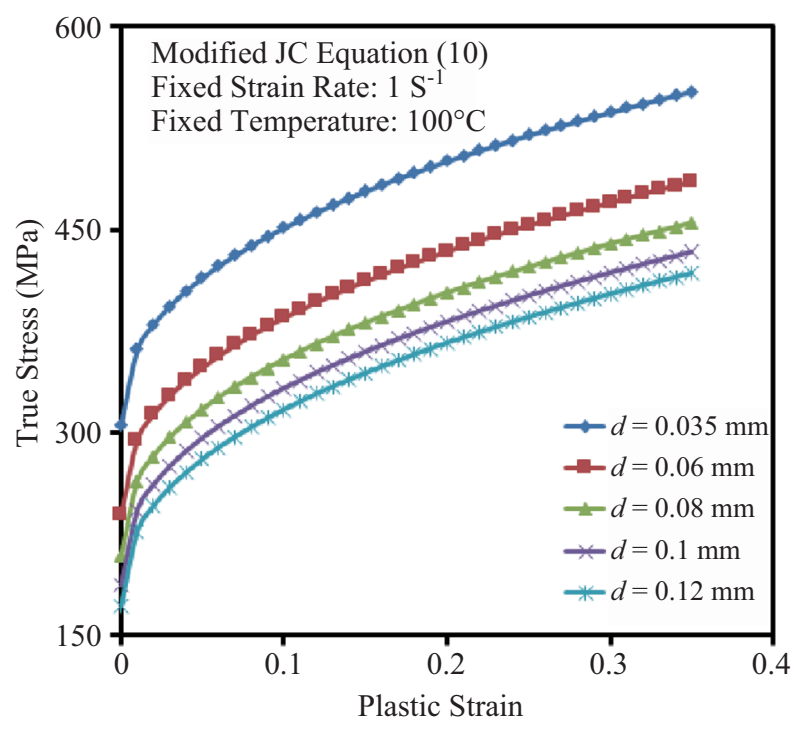

Fig. 5 True stress-strain behavior of AA2024 using modified Johnson-Cook equation.

Figure 4 represents the variation in yield strength as a function of grain size ranging from 0.035 to $0.12 \mathrm{~mm}$ using the Hall-Petch eq. (9). It may be noted that the yield strength drops sharply up to the grain size of $0.035 \mathrm{~mm}$. Beyond this point, the trend shows a moderate decrease until the grain size reaches $0.1 \mathrm{~mm}$ and finally appears to be stable from $0.12 \mathrm{~mm}$ onward. The selection of the grain size, of the order of $0.1 \mathrm{~mm}$, is based upon the evolution of microstructure within the machined chip, Zhang et al. [26].

Figure 5 shows the stress-strain curves using the modified JC model for selected grain sizes. Finest grain size of $0.035 \mathrm{~mm}$ improves the yield strength and hence increases the strain hardening effect. Yield strength decreases as the grain size increases and a resulting decreasing trend is also observed for the strain hardening curves (Fig. 5). 


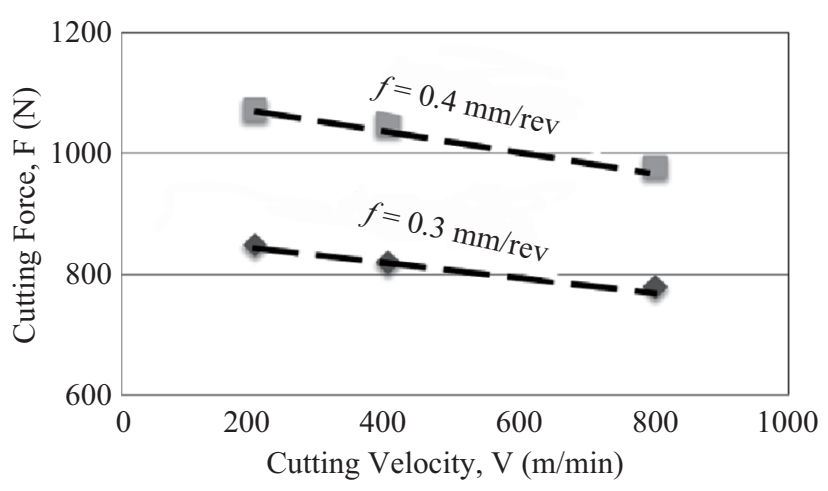

(a)

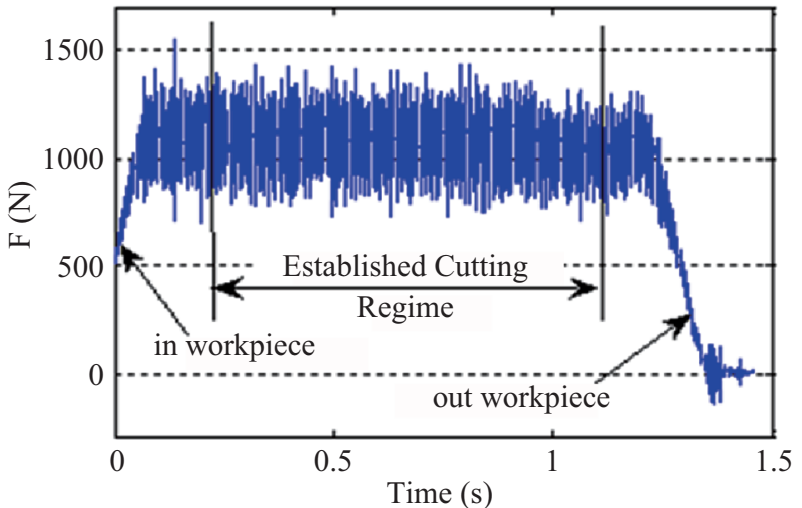

(b)

Fig. 6 Cutting forces for various cutting speeds and feed rates.

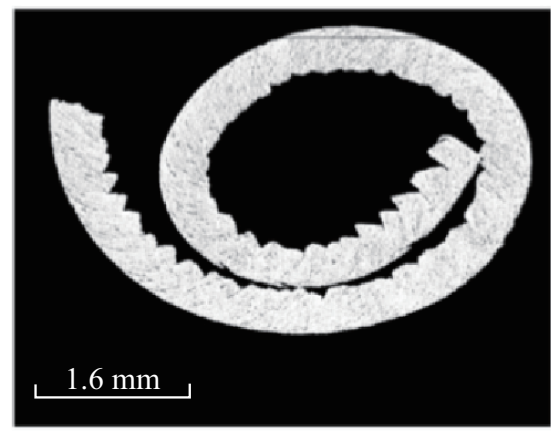

(a)

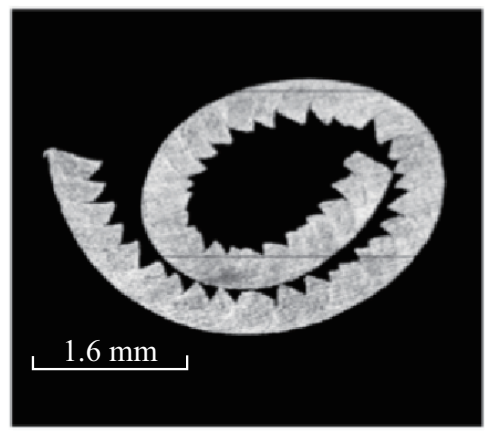

(b)

Fig. 7 Chip morphology for $f=0.4 \mathrm{~mm} / \mathrm{rev}$ (a) $V=200 \mathrm{~m} / \mathrm{min}$ and (b) $V=800 \mathrm{~m} / \mathrm{min}$ [18].

\section{EXPERIMENTAL RESULTS}

Orthogonal turning experiments for the cutting speeds $(V)$ at $200,400,800 \mathrm{~m} / \mathrm{min}$, the feed rates at 0.3 and $0.4 \mathrm{~mm} / \mathrm{rev}$ and a fixed depth of cut $\left(a_{p}\right)$ of $4 \mathrm{~mm}$ were performed. Turning insert cutting edge was both orthogonal to the feed rate and the cutting speed (to ensure the orthogonal turning conditions). Cutting forces were registered by using a standard dynamometer. The measured average cutting forces for various cutting parameters are shown in Fig. 6(a). These average cutting forces represent only the well-established cutting regime realized during the cutting process, Fig. 6(b). The photographs of chip morphology for $f=0.4 \mathrm{~mm} / \mathrm{rev}$ at $V=$ $200 \mathrm{~m} / \mathrm{min}$ and $V=800 \mathrm{~m} / \mathrm{min}$ are shown in Figs. 7(a) and (b), respectively [18]. Further details on the experimental approach can be found in the work of Asad [17-18].

\section{FINITE ELEMENT ANALYSIS}

A 2D analysis was performed by using a commercially available FE software ABAQUS/Explicit. FE simulations of the turning process of AA2024 for three cutting speeds $(200,400,800 \mathrm{~m} / \mathrm{min})$ and two cutting feeds $(0.3$ and $0.4 \mathrm{~mm} / \mathrm{rev})$ were carried out. The FE model consisted of a workpiece and a tool as shown in Fig. 8. The workpiece geometry was further divided into three parts, i.e. the chip, the damage zone, and the workpiece support. A fully coupled temperature-displacement analysis was performed using the plane strain linear quadrilateral elements (CPE4RT) without any re-meshing algorithm. The size of the damage zone was kept of the order of tool tip radius, $\mathrm{Li}$ et al. [27]. The boundary and imposed loading conditions are also shown in Fig. 8.

During the analysis, the tool comes in contact with all three parts of the workpiece, i.e. the chip, the damage zone, and the workpiece support. Moreover, when the chip curls onto itself, it also makes what is known as a 'self-contact'. A coulomb friction criterion is used to define the contact interactions among tool-chip-workpiece (Deng et al. [28]). The elements in the damage zone would disappear once the failure criteria described in the JC model is satisfied. The JC material parameters of AA2024 for damage criteria are given in Table 1. The mechanical properties for AA2024 workpiece and tungsten carbide tool are given in Table 2.

\section{RESULTS AND DISCUSSION}

In this section, the results obtained from various FE 


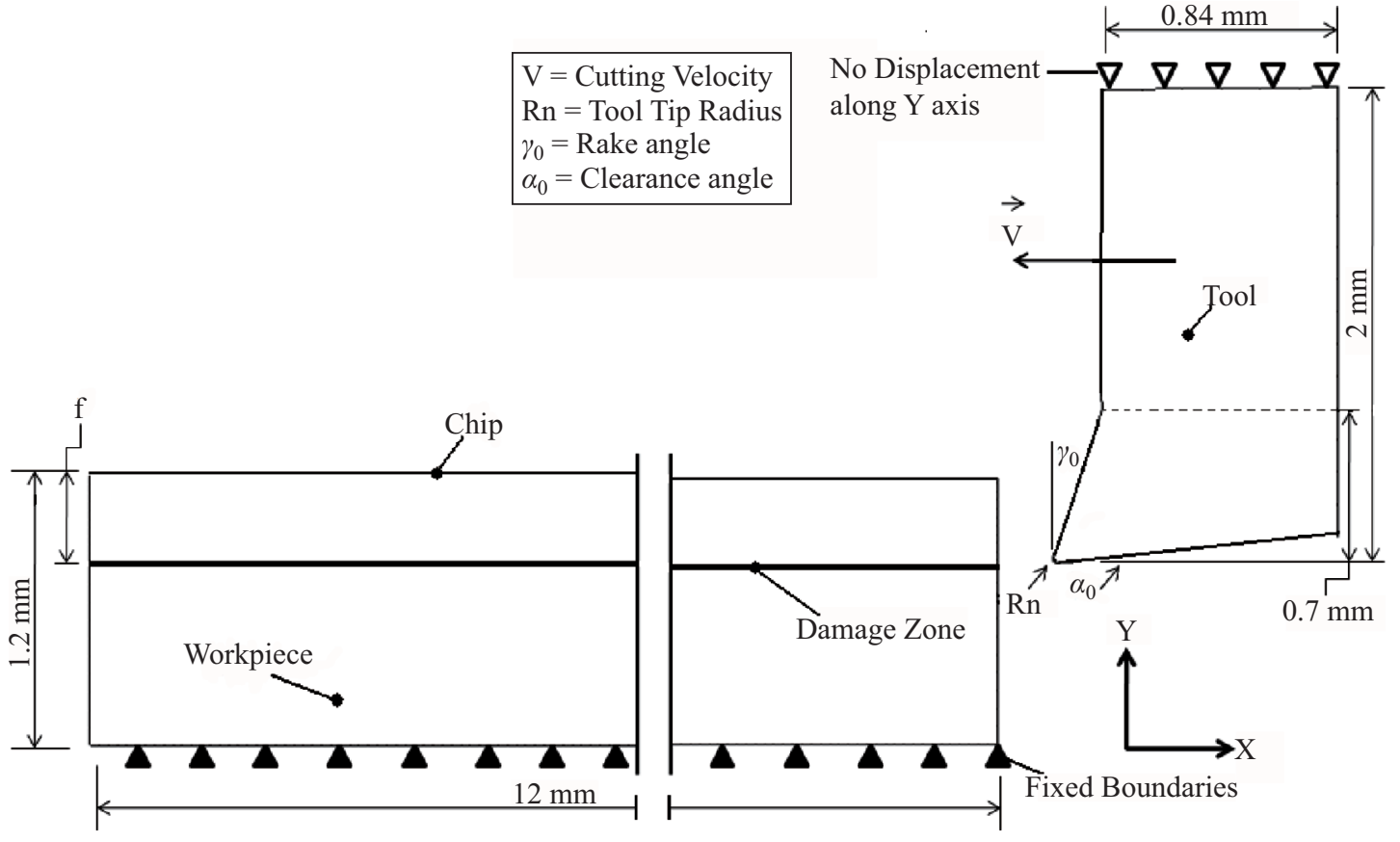

Fig. 8 Workpiece and tool geometries.

Table 2 Work piece and Tool properties $[17,29]$

\begin{tabular}{|c|c|c|}
\hline Physical parameter & Work piece (AA2024) & $\begin{array}{c}\text { Tool } \\
\text { (Tungsten Carbide insert) }\end{array}$ \\
\hline Density, $\rho\left(\mathrm{Kg} / \mathrm{m}^{3}\right)$ at $25^{\circ} \mathrm{C}$ & 2700 & 0.22 \\
\hline Poisson ratio, $v$ & 0.33 & 400 \\
\hline $\begin{array}{c}\text { Specific heat, } \\
C_{p}(T)\left(\mathrm{JKg}^{-1}{ }^{\circ} \mathrm{C}^{-1}\right)\end{array}$ & $C_{p}=0.557 T+877.6$ & 50 \\
\hline $\begin{array}{c}\text { Thermal conductivity } \\
\lambda(T)\left(\mathrm{Wm}^{-1} \mathrm{C}^{-1}\right)\end{array}$ & $25 \leq T \leq 300: \lambda=0.247 T+114.4$ & - \\
\hline Expansion, $\alpha\left(\mu \mathrm{m}^{-1} \mathrm{~m}^{-1} \mathrm{C}^{-1}\right)$ & $300 \leq T \leq T_{\mathrm{melt}}: \lambda=-0.125 T+226.0$ & 25 \\
\hline$T_{\text {melt }}\left({ }^{\circ} \mathrm{C}\right)$ & $\alpha+8.9 \times 10^{-3} T+22.2$ & - \\
\hline$T_{\text {room }}\left({ }^{\circ} \mathrm{C}\right)$ & 520 & - \\
\hline$K_{I C}(\mathrm{MPa} \sqrt{\mathrm{m}})$ & 25 & 26 \\
\hline$K_{I I C}(\mathrm{MPa} \sqrt{\mathrm{m}})$ & 37 & \\
\hline
\end{tabular}

simulations at different speeds and feeds are discussed in detail.

\subsection{Classical Johnson-Cook Model}

Figure 9 presents the evolution of cutting force vs. time for $0.4 \mathrm{~mm} / \mathrm{rev}$ feed and $800 \mathrm{~m} / \mathrm{min}$ speed. The FE results are found to be in a good agreement with the experimental ones. Figure 10 shows the comparison of the average cutting forces with the cutting speed for both the numerical and experimental results at the feed rate of $0.3 \mathrm{~mm} / \mathrm{rev}$. Although, the FE results show a slightly increasing trend with increasing cutting speeds, but these are still in the acceptable range if compared with the experimental ones.

\subsection{Modified Johnson-Cook Model}

The FE results using modified JC material model are being discussed here in detail for various selected grain sizes. Figure 11 shows the evolution of cutting force with time at the cutting speed of $200 \mathrm{~m} / \mathrm{min}$, the feed rate of $0.4 \mathrm{~mm} / \mathrm{rev}$ and the grain size ranging from $0.035 \mathrm{~mm}$ to $0.12 \mathrm{~mm}$. The decreasing trend of the cutting forces 


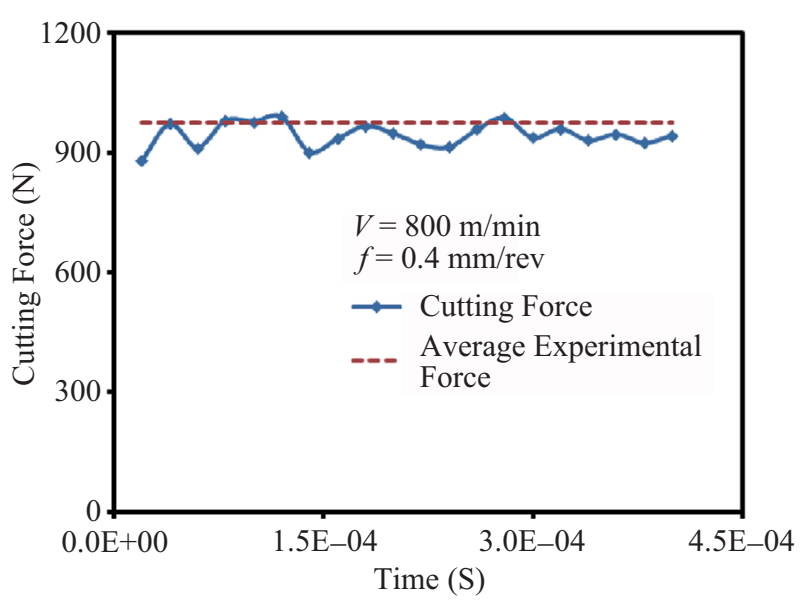

Fig. 9 Cutting force vs. time.

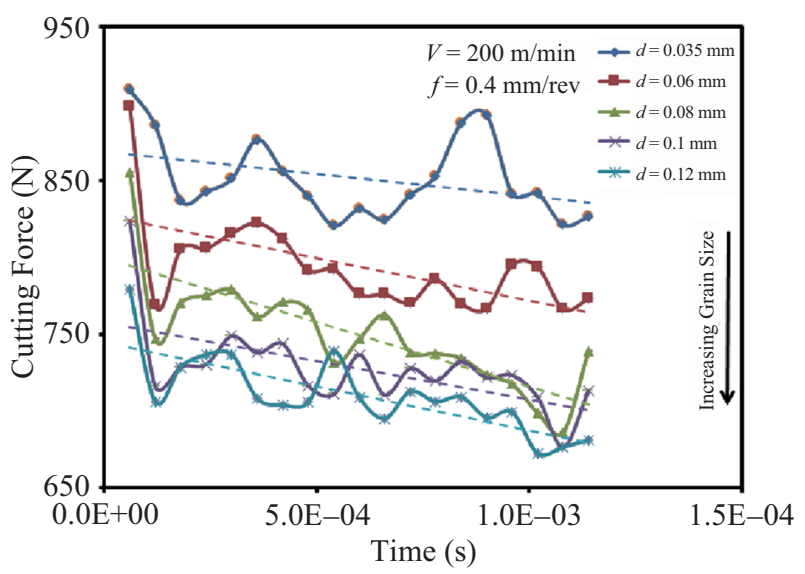

Fig. 11 Cutting force vs. time for different grain sizes $(f=0.4 \mathrm{~mm} / \mathrm{rev})$.

with an increase in grain size is evident from the figure. The difference between the average cutting forces becomes smaller as the grain size increases. This behavior is consistent with the yield strength trend as depicted by Hall-Petch Eq. (9), see Fig. 4.

Figure 12 presents the average cutting forces obtained from FE analysis for different cutting speeds (200, 400, $800 \mathrm{~m} / \mathrm{min})$, grain sizes $(0.035,0.06,0.08,0.1$ and $0.12 \mathrm{~mm}$ ) and the feed rate of $0.4 \mathrm{~mm} / \mathrm{rev}$. Note that the magnitude of cutting forces decreases as the grain size increases for all the cutting speeds. This decreasing trend is due to the decreasing yield strength values as a function of the material grain size, see Eq. (9). The variation of results between the modified $\mathrm{JC}$ and the classical JC models can be observed from Fig. 12. It may be observed that the difference ranges from $5.5 \%$ to $19.3 \%$ at a speed of $400 \mathrm{~m} / \mathrm{min}$ with different grain sizes.

Similarly, the Fig. 13 presents the evolution of cutting forces with time for $400 \mathrm{~m} / \mathrm{min}$ cutting speed, $0.3 \mathrm{~mm} / \mathrm{rev}$

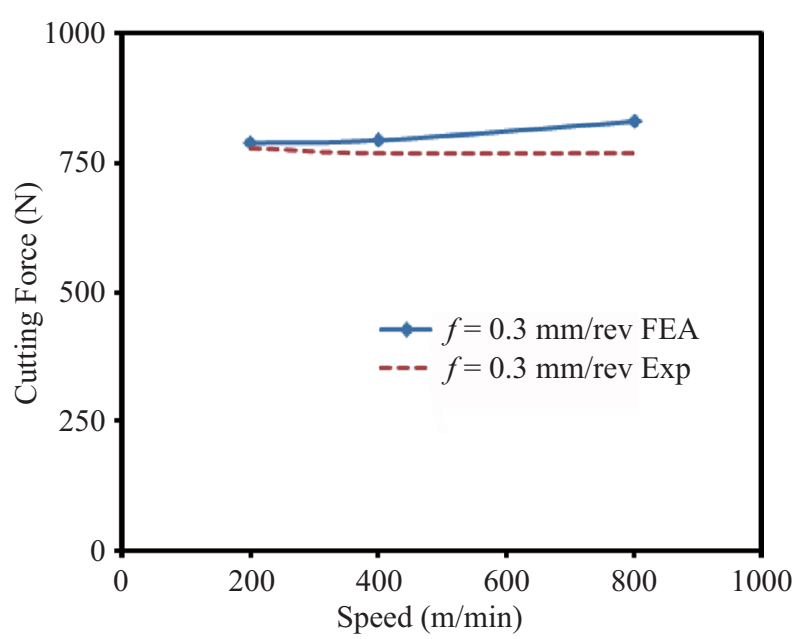

Fig. 10 Cutting force vs. speed.

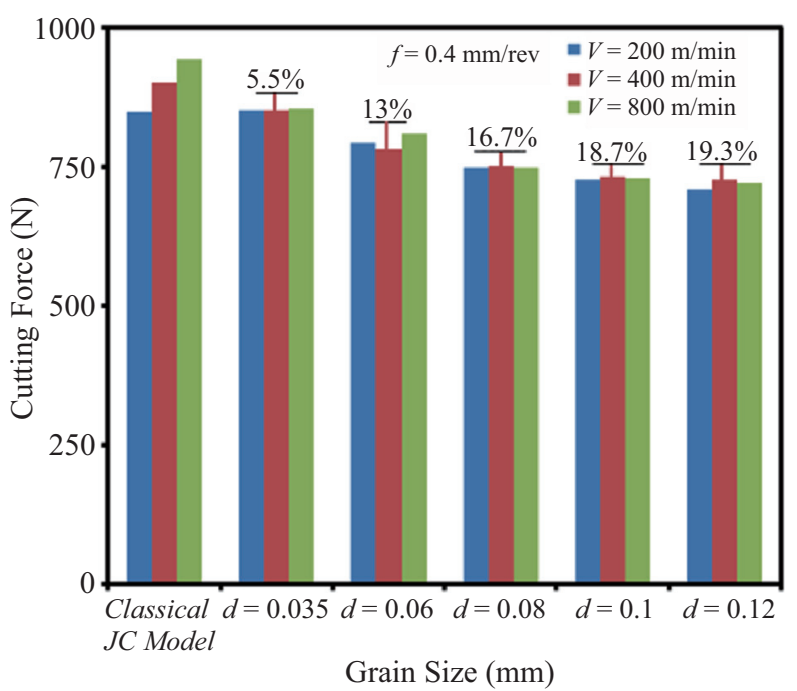

Fig. 12 Cutting force vs. grain size with different speeds $(f=0.4 \mathrm{~mm} / \mathrm{rev})$.

feed and $0.035,0.06,0.08,0.1$ and $0.12 \mathrm{~mm}$ grain sizes. Figure 14, shows the average cutting forces for three different cutting speeds $(200,400,800 \mathrm{~m} / \mathrm{min})$ as a function of grain sizes for $0.3 \mathrm{~mm} / \mathrm{rev}$ feed. Again, a similar trend is observed as depicted by Hall-Petch relation. The average reaction forces calculated using the modified JC model varies from $19.3 \%$ to $30.4 \%$ at $400 \mathrm{~m} / \mathrm{min}$ cutting speed with different grain sizes.

Figure 15 shows the Von-Mises stress profile in the workpiece geometry for different grain sizes and for $V=400 \mathrm{~m} / \mathrm{min}$ and $f=0.4 \mathrm{~mm} / \mathrm{rev}$. Given the yield strength dependency upon the grain size, the maximum stress value varies from $558 \mathrm{MPa}$ to $438 \mathrm{MPa}$ for grain sizes of $0.035 \mathrm{~mm}$ and $0.12 \mathrm{~mm}$, respectively.

\subsection{Shear Zone}

Figure 16 shows the shear stress profile for $0.4 \mathrm{~mm} / \mathrm{rev}$ feed, $200 \mathrm{~m} / \mathrm{min}$ cutting speed and for different grain sizes. A highly stressed zone, called the primary shear 


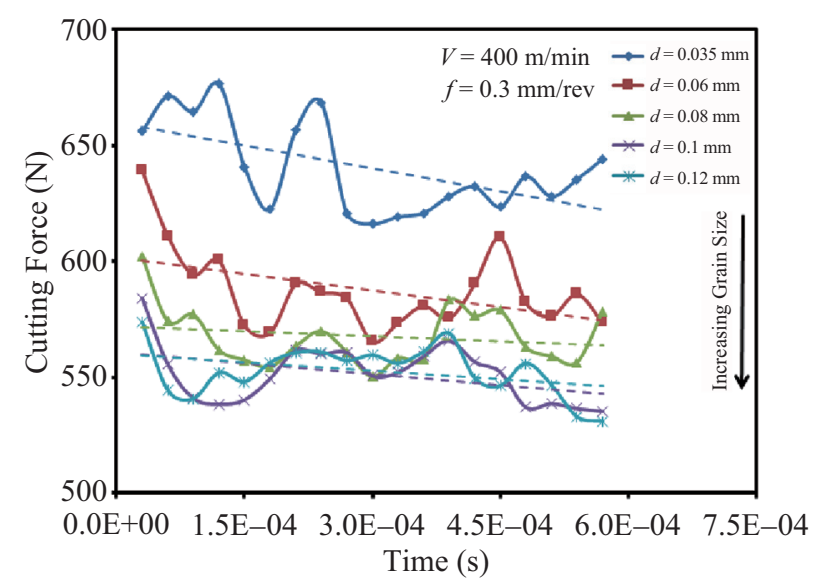

Fig. 13 Cutting force vs. time for different grain sizes $(f=0.3 \mathrm{~mm} / \mathrm{rev})$.

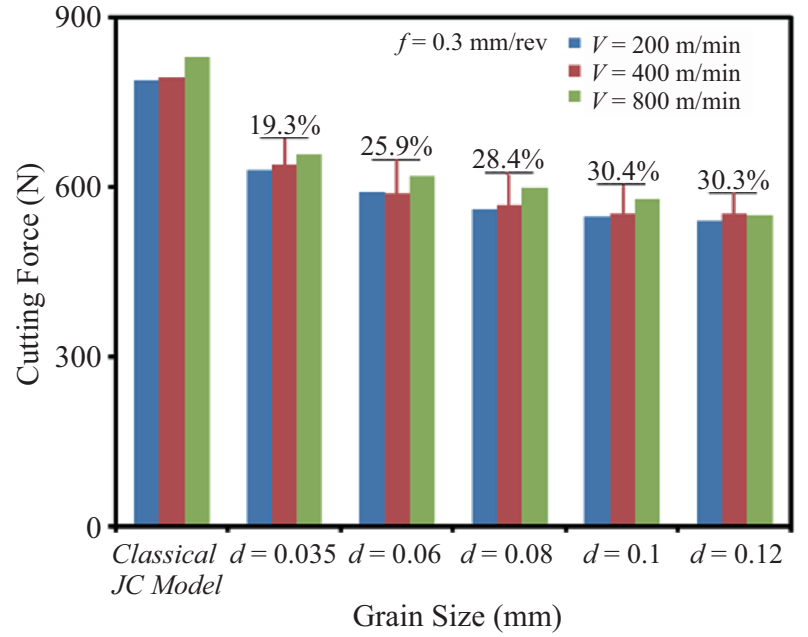

Fig. 14 Cutting force vs. grain size with different speeds $(f=0.3 \mathrm{~mm} / \mathrm{rev})$.
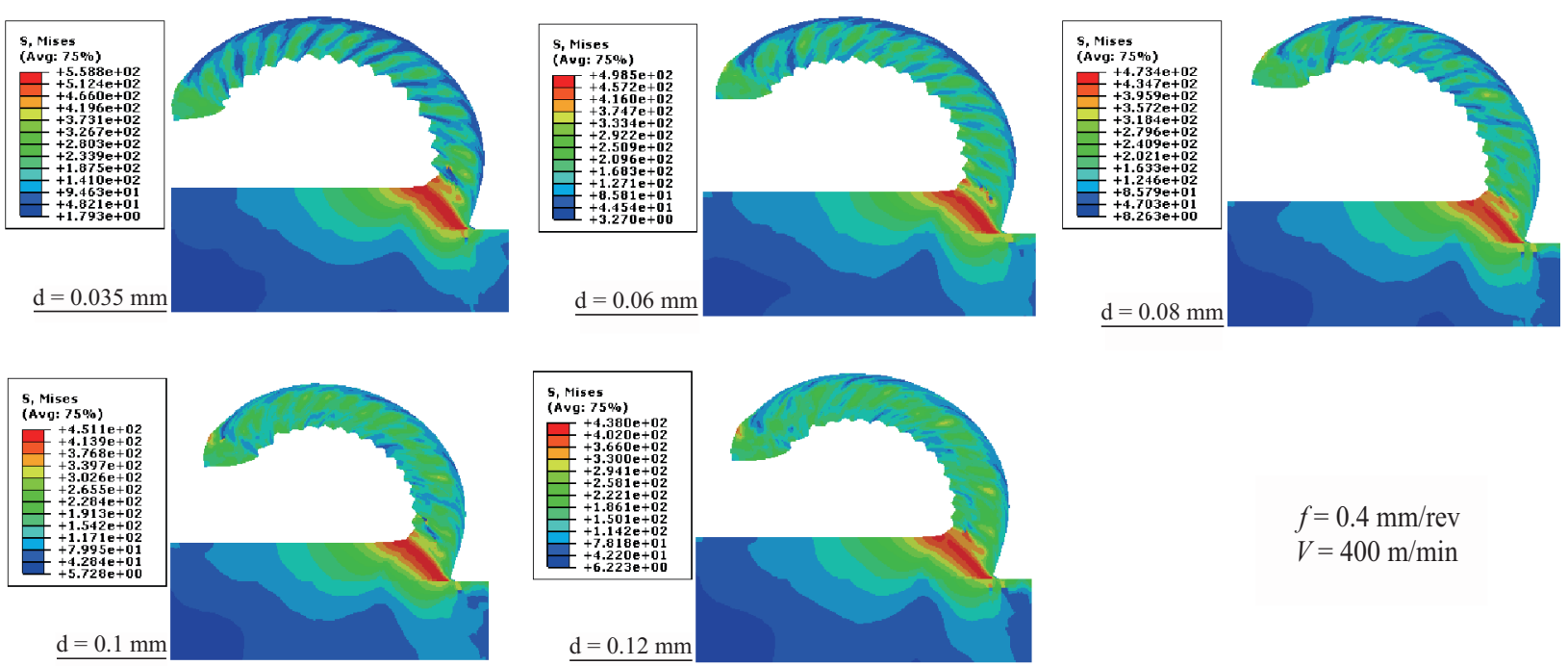

\section{$f=0.4 \mathrm{~mm} / \mathrm{rev}$ $V=400 \mathrm{~m} / \mathrm{min}$}

Fig. 15 Mises stress profile for different grain sizes, $V=400 \mathrm{~m} / \mathrm{min}, f=0.4 \mathrm{~mm} / \mathrm{rev}$.
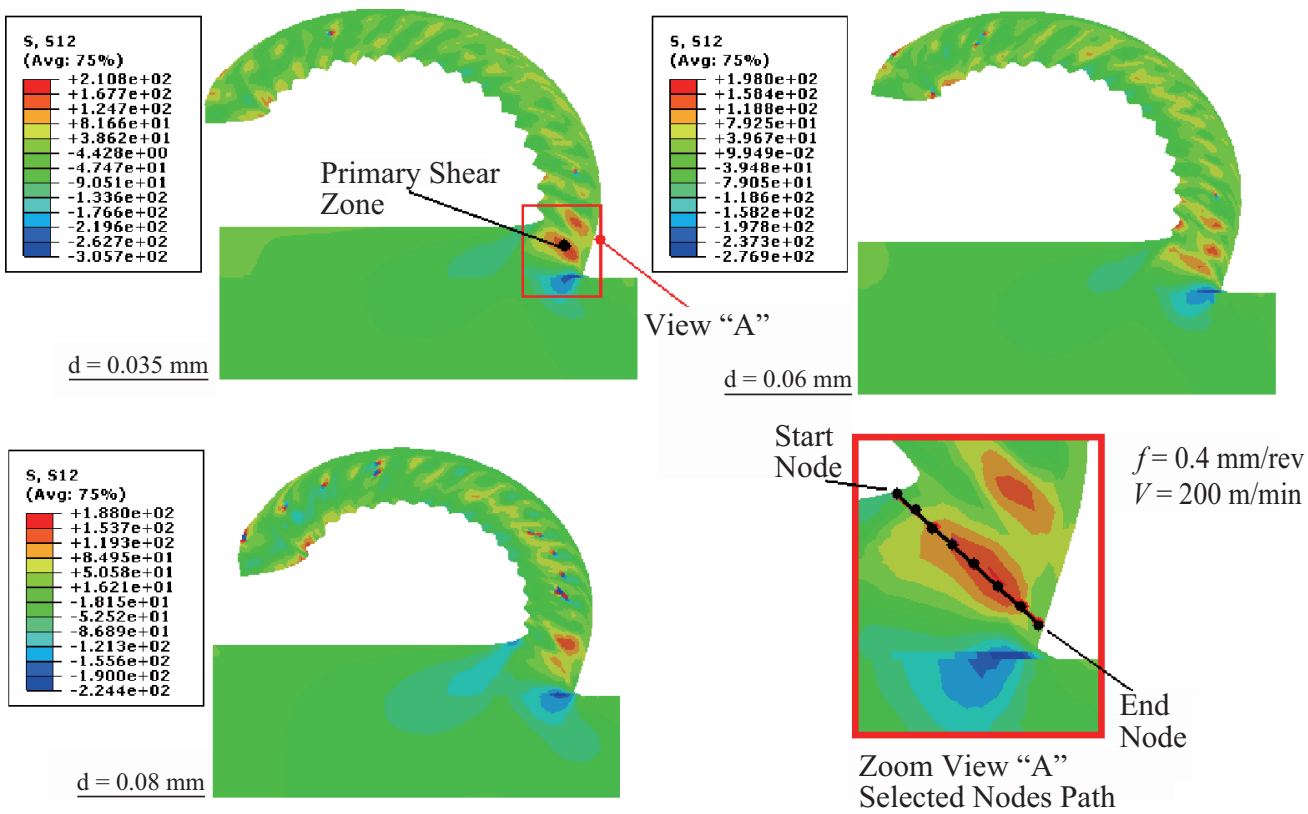

Fig. 16 Shear stress profile for different grain sizes, $V=200 \mathrm{~m} / \mathrm{min}, f=0.4 \mathrm{~mm} / \mathrm{rev}$. 


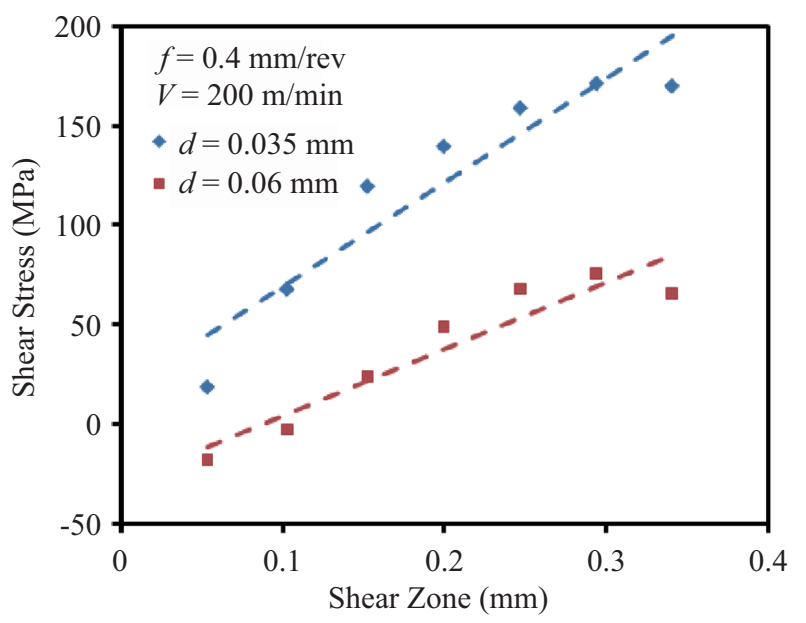

(a)

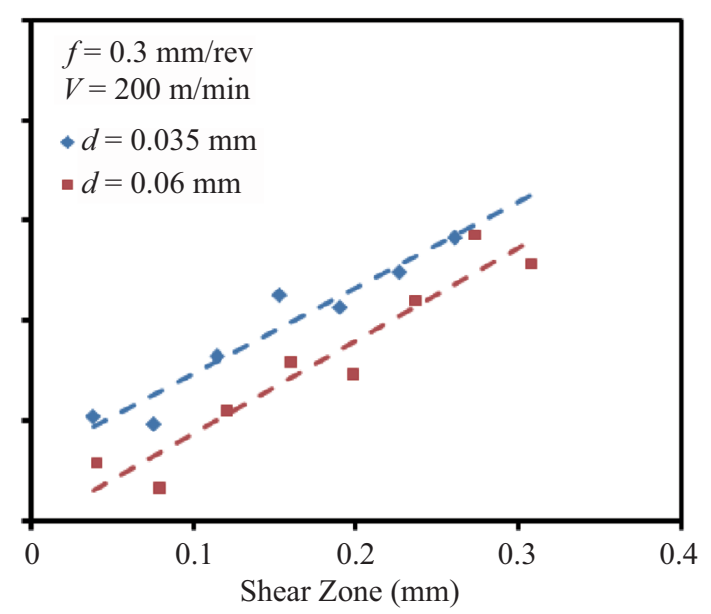

(b)

Fig. 17 Evolution of shear stress in shear zone.

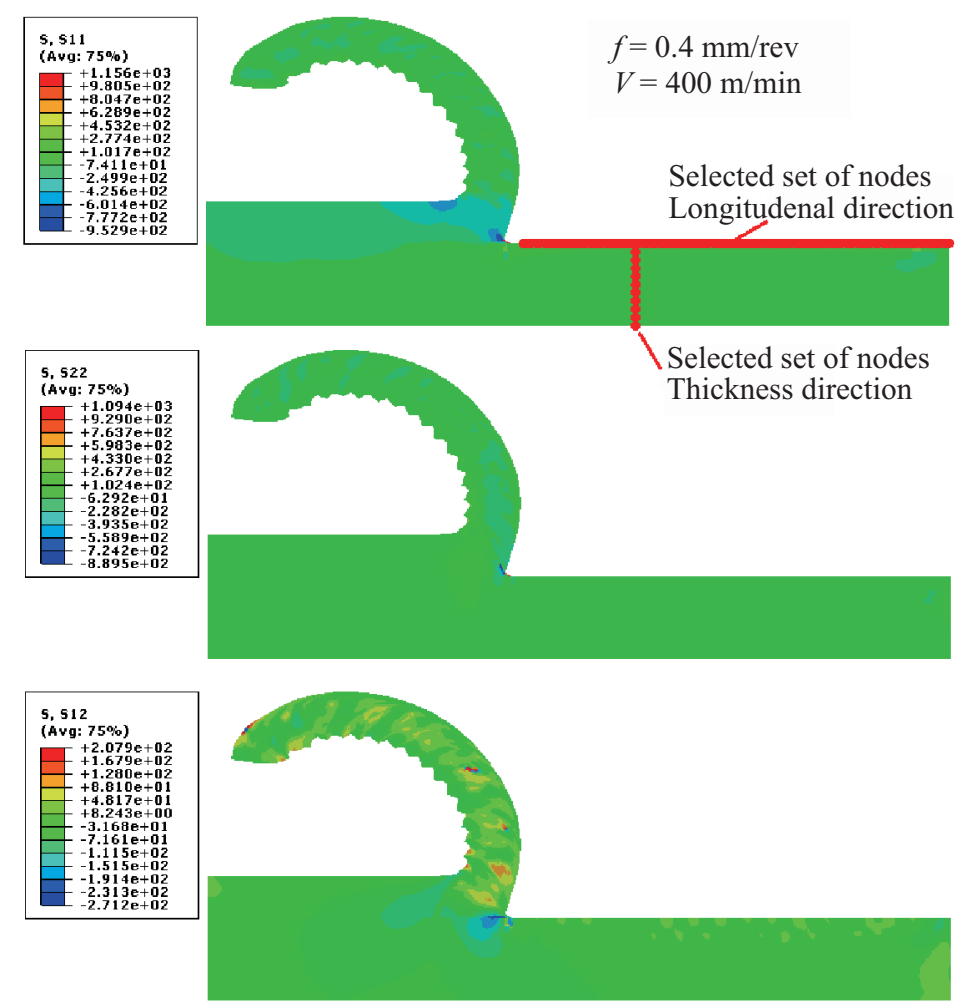

Fig. 18 Machining induced residual stresses in workpiece, $V=400 \mathrm{~m} / \mathrm{min}, f=0.4 \mathrm{~mm} / \mathrm{rev}$.

zone, within the chip near the cutting tool tip may be observed from the figure. The stresses in the primary shear zone are considerably higher in comparison to the rest of the workpiece. The shear stress values for the selected set of nodes at $0.4 \mathrm{~mm} / \mathrm{rev}$ and $0.3 \mathrm{~mm} / \mathrm{rev}$ are shown in Fig. 17 for different grain sizes. The distance between the start and last nodes is equal to the length of the selected shear zone, see Fig. 16. It can be seen from the Fig. 17(a) that the shear stress value is higher for the finer grain size. It may also be observed that the maximum shear stress occurs within the mid-section of the chip and not on the surface. The chip with $0.3 \mathrm{~mm} / \mathrm{rev}$ feed for different grain sizes, Fig. 17(b), exhibits an identical behavior.

\subsection{Machining Induced Residual Stresses}

Figure 18 shows the contour plots of residual stresses $\left(\sigma_{11}, \sigma_{22}, \sigma_{12}\right)$ for $0.4 \mathrm{~mm} / \mathrm{rev}$ feed, $400 \mathrm{~m} / \mathrm{min}$ cutting speed and $0.035 \mathrm{~mm}$ grain size. Two sets of nodes along the longitudinal and the chip thickness directions are selected to observe the machining induced residual stresses. Figure 19 presents the residual stresses in the longitudinal direction for two different cutting feeds, i.e. $0.3 \mathrm{~mm} / \mathrm{rev}$ and $0.4 \mathrm{~mm} / \mathrm{rev}$. Both show similar trends, except that the magnitude of stresses is higher in case of 


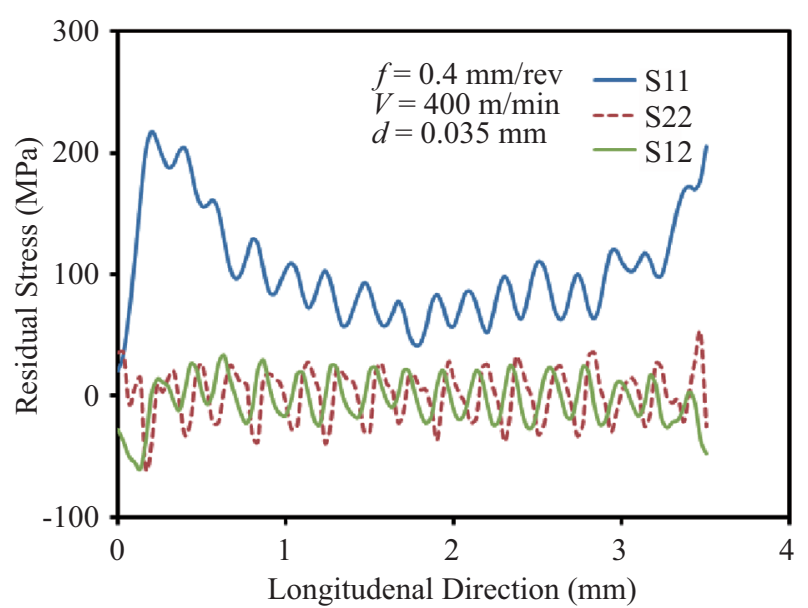

(a)

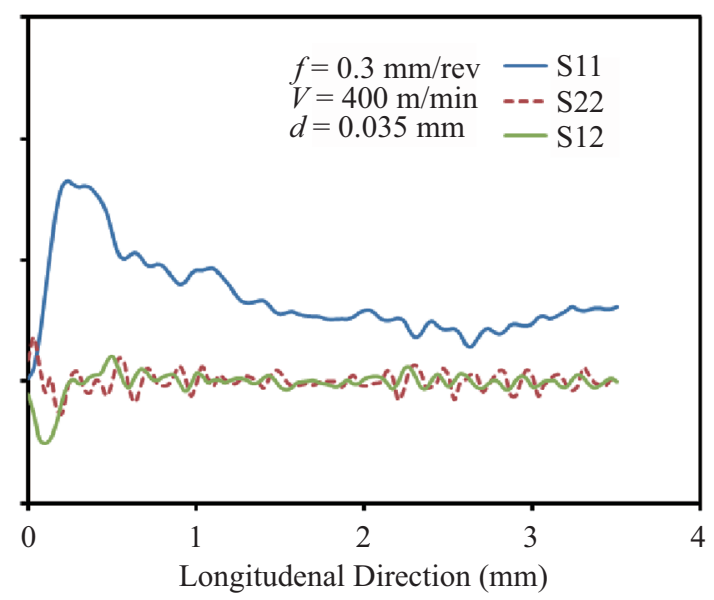

(b)

Fig. 19 Machining induced residual stress in longitudinal direction.

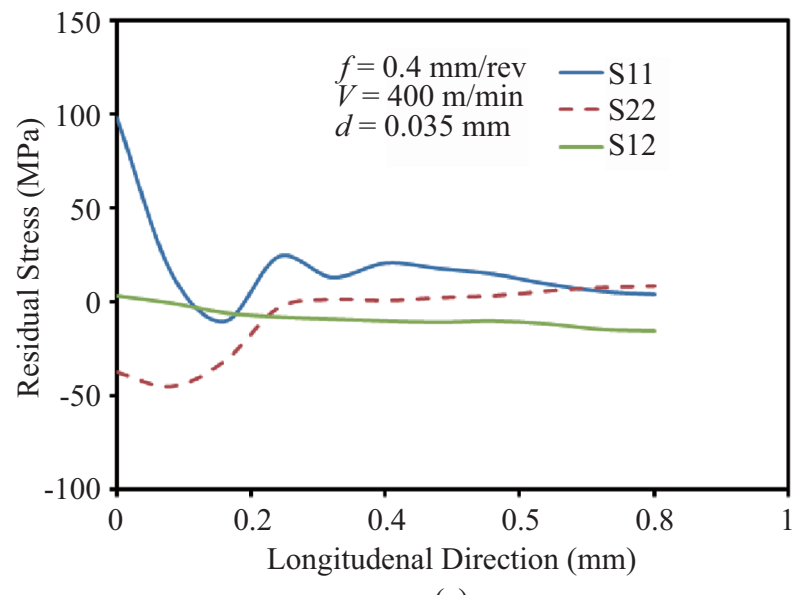

(a)

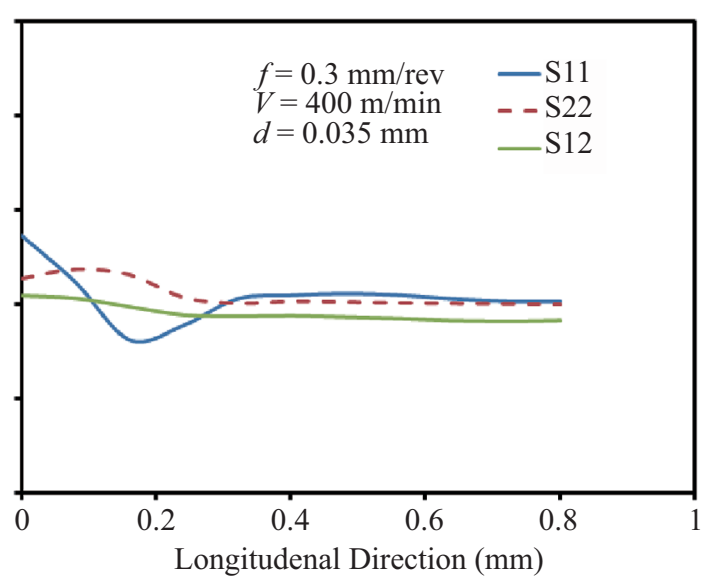

(b)

Fig. 20 Machining induced residual stress in the chip thickness direction.

the large cutting feed $(0.4 \mathrm{~mm} / \mathrm{rev})$. From this figure, it can be assessed that normal stress $\sigma_{11}$ which is also in longitudinal direction plays a significant role in limiting the residual stress level while the other stresses $\sigma_{22}$ and $\sigma_{12}$ just oscillate in tension and compression with low magnitudes.

Figure 20 shows the residual stress state in chip thickness direction for $0.035 \mathrm{~mm}$ grain size and $0.3 \mathrm{~mm} / \mathrm{rev}$ and $0.4 \mathrm{~mm} / \mathrm{rev}$ feed. Again, it may be noted that the normal stress $\sigma_{11}$ is the most significant component that governs the residual stress level. As expected, the higher magnitudes are observed at the top surface of the workpiece and their value reduces rapidly below the top surface. It may also be observed that the stress magnitude is consistently higher for $0.4 \mathrm{~mm} / \mathrm{rev}$ feed in comparison to that for $0.3 \mathrm{~mm} / \mathrm{rev}$. This also indicates that cutting tools experience higher reaction forces as the feed is increased.

\section{CONCLUSIONS}

The change in the grain structure significantly affects the yield strength of parent material. Classical JC plasticity model coupled with damage evolution law can simulate the elasto-plastic behavior and the failure of ductile materials. However, in the present study, a modified JC model is discussed that can accommodate the effect of grain size by incorporating the change in yield strength of the material. Predictions based on FE analysis for various feed, cutting speeds and different grain sizes are made for turning process of aluminum alloy 2024. Nevertheless, the strategy presented can be applied to a wide range of metals and alloys. From the simulation results, it was observed that the smaller grain size significantly affects the yield strength and, hence, the cutting tool experiences a greater reaction force. This information is important from the perspective of process engineer who needs to design the process parameter for machining operation.

A higher feed rate gives rise to very high shear stresses, which eventually require more cutting power and lead to an increased tool wear. A lower feed rate, however, can also present similar disadvantages if the grain size turns out to be extremely fine. The present work suggests a numerical solution to such problems, where an average cutting force can be calculated based 
upon the modified JC model. The proposed scheme takes into account the grain size based material properties and the machining parameters. A precise knowledge of cutting forces is likely not only to make the choice of machining parameters and the tool selection easier but also cost-effective.

\section{NOMENCLATURE}

$B \quad$ Hardening modulus, $\mathrm{MPa}$;

$C \quad$ Strain rate dependency coefficient;

$C_{p} \quad$ Specific heat, $\mathrm{J} \mathrm{Kg}^{-1}{ }^{\circ} \mathrm{C}^{-1}$;

$D \quad$ Damage evolution parameter;

$D_{1} \sim D_{5} \quad$ Coefficients of Johnson-Cook material shear failure initiation criterion;

d $\quad$ Grain size, $\mathrm{mm}$;

E Young's Modulus, MPa;

$f \quad$ Feed, mm/rev;

$G_{f} \quad$ Fracture energy, KJ.m ${ }^{-2}$;

$K_{I C} \quad$ Mode I fracture toughness, MPa.m ${ }^{1 / 2}$;

$K_{I I C} \quad$ Mode II Fracture toughness, MPa.m ${ }^{1 / 2}$;

$K_{H P} \quad$ Hall-Petch material parameter, MPa.mm ${ }^{1 / 2}$;

$m \quad$ Thermal softening coefficient;

$n \quad$ Work-hardening exponent;

$P \quad$ Hydrostatic pressure, MPa;

$T \quad$ Temperature at a given calculation instant, ${ }^{\circ} \mathrm{C}$;

$T_{\text {room }} \quad$ Reference ambient temperatures, ${ }^{\circ} \mathrm{C}$;

$T_{\text {melt }} \quad$ Melting temperatures, ${ }^{\circ} \mathrm{C}$;

$\bar{u} \quad$ Equivalent plastic displacement, $\mathrm{mm}$;

$\bar{u}_{f} \quad$ Equivalent plastic displacement at failure, $\mathrm{mm}$;

$V \quad$ Cutting speed, mm. $\mathrm{min}^{-1}$;

$\alpha \quad$ Coefficient of thermal expansion, $\mu \mathrm{m} . \mathrm{mm}^{-1}{ }^{\circ} \mathrm{C}^{-1}$;

$\bar{\varepsilon} \quad$ Equivalent plastic strain;

$\dot{\bar{\varepsilon}} \quad$ Plastic strain rate;

$\dot{\bar{\varepsilon}_{0}} \quad$ Reference strain rate;

$\bar{\varepsilon}_{0 i} \quad$ Plastic strain at damage initiation;

$\lambda$

$v$

$\rho$

$\rho$

$\sigma$

$\sigma_{y}$

$\sigma_{o}$

$\bar{\sigma}$

$\omega$

Poisson's ratio;

Density, Kg.m ${ }^{-3}$;

Stress, $\mathrm{MPa}$;

Yield strength, MPa;

Friction stress, MPa;

Equivalent plastic stress, $\mathrm{MPa}$;

Damage initiation criterion;

\section{REFERENCES}

1. Hall, E. O., "The deformation and ageing of mild Steel III-discussion of results," Proceedings of the Physical Society, Section B, 64, pp. 747-753 (1951).

2. Petch, N. J., "The cleavage strength of polycrystals," The Journal of the Iron and Steel Institute, 174, pp. 25-28 (1953).

3. Vivekananda, K., Arka, G. N. and Sahoo, S. K., "Finite element analysis and process parameters optimization of ultrasonic vibration assisted turning (UVT)," Procedia Materials Science, 6, pp. 19061914 (2014).

4. Stalin John, M. R., Shrivastava, K., Nilanjan, B., Madhukar, P. D. and Vinayagam, B. K., "Finite element method-based machining simulation for analyzing surface roughness during turning operation with HSS and carbide insert tool," Arabian Journal for Science and Engineering, 38, pp. 1615-1623 (2013).

5. Agmell, M., Ahadi, A. and Stahl, J. -E., "Identification of plasticity constants from orthogonal cutting and inverse analysis," Mechanics of Materials, 77, pp. 43-51 (2014)

6. Yin, C. J., Zheng, Q. C. and Hu, Y. H., "Finite element simulation of Titanium alloy turning process," Applied Mechanics and Materials, 391, pp. 14-17 (2013).

7. Wu, H. and Guo, L., "Machinability of Titanium alloy TC21 under orthogonal turning process," $M a$ terials and Manufacturing Processes, 29, pp. 14411445 (2014).

8. Ijaz, H., Zain-ul-abdein, M., Saleem, W., Asad, M. and Mabrouki, T., "A numerical approach on parametric sensitivity analysis for an aeronautic aluminium alloy turning process," Mechanika, 22, doi: http://dx.doi.org/10.5755/j01.mech.22.2.12825 (2016).

9. Liu, K. and Melkote, S. N., "Finite element analysis of the influence of tool edge radius on size effect in orthogonal micro-cutting process," International Journal of Mechanical Sciences, 49, pp. 650-660 (2007).

10. Lai, X., Li, H., Li, C., Lin, Z. and Ni, J., "Modelling and analysis of micro scale milling considering size effect, micro cutter edge radius and minimum chip thickness," International Journal of Machine Tools and Manufacture, 48, pp. 1-14 (2008).

11. Subbiah, S. and Melkote, S. N., "Effect of finite edge radius on ductile fracture ahead of the cutting tool edge in micro-cutting of A12024-T3," Materials Science and Engineering: A, 474, pp. 283-300 (2008).

12. Meng, Q. and Wang, Z., "Extended finite element method for power-law creep crack growth," Engineering Fracture Mechanics, 127, pp. 148-160 (2014)

13. Ijaz, H., Asad, M., Gornet, L. and Alam, S. Y., "Prediction of delamination crack growth in carbon/fiber epoxy composite laminates using non-local interface damage model," Mechanics \& Industry, 15, pp. 293-300 (2014).

14. Johnson, G. R. and Cook, W. H., "Fracture characteristics of three metals subjected to various strains, strain rates, temperatures and pressures," Engineering Fracture Mechanics, 21, pp. 31-48 (1985). 
15. Zhang, Y., Outeiro, J. C. and Mabrouki, T., "On the selection of Johnson-Cook constitutive model parameters for Ti-6Al-4 V using three types of numerical models of orthogonal cutting," Procedia CIRP, 31, pp. 112-117 (2015).

16. Shrot, A. and Baker, M., "Determination of Johnson-Cook parameters from machining simulations," Computational Materials Science, 52, pp. 298-304 (2012).

17. Asad, M., "Elaboration of concepts and methodologies to study peripheral down-cut milling process from macro-to-micro scales," $\mathrm{PhD}$ Dissertation, INSALyon, France (2010).

18. Mabrouki, T., Girardin, F., Asad, M. and Rigal, J.-F., "Numerical and experimental study of dry cutting for an aeronautic aluminium alloy (A2024-T351)," International Journal of Machine Tools \& Manufacture, 48, pp. 1187-1197 (2008).

19. Han, Z. Y., Huang, X. G., Cao, Y. G. and Xu, J. Q., "A non linear cumulative evolution model for corrosion fatigue damage," Journal of Zhejiang University Science A, 15, pp. 447-453 (2014).

20. Hillerborg, A., Modeer, M. and Petersson, P. -E., "Analysis of crack formation and crack growth in concrete by means of fracture mechanics and finite elements," Cement \& Concrete Research, 6, pp. 773-781 (1976).

21. Shi, J. and Liu, C. R., "On predicting chip morphology and phase transformation in hard machining," The International Journal of Advanced Manufacturing Technology, 27, pp. 645-654 (2006).

22. Hansen, N., "The effect of grain size and strain on the tensile flow stress of aluminium at room temperature," Acta Metallurgica, 25, pp. 863-869 (1977).

23. Simar, A. et al., "Integrated modeling of $6 \mathrm{xxx}$ series
Al alloys: process, microstructure and properties," Progress in Materials Science, 57, pp. 95-183 (2012).

24. Deschamps, A. and Brechet, Y., "Influence of predeformation and ageing of $\mathrm{Al}-\mathrm{Zn}-\mathrm{Mg}$ alloy-II. Modeling of precipitation kinetics and yield stress," Acta Materialia, 4, pp. 293-305 (1999).

25. Zain-ul-abdein, M. and Nélias, D., "Effect of coherent and incoherent precipitates upon the stress and strain fields of 6xxx aluminium alloys: a numerical analysis," International Journal of Mechanics and Materials in Design, 12, pp. 255-271 (2016).

26. Zhang, X., Wu, S., Wang, H. and Liu, C. R., "Predicting the Effects of Cutting Parameters and Tool Geometry on Hard Turning Process Using Finite Element Method," Journal of Manufacturing Science and Engineering, 133, 041010 (2011).

27. Li, K., Gao, X.-L. and Sutherland, J. W., "Finite element simulation of the orthogonal metal cutting process for qualitative understanding of the effects of crater wear on the chip formation process," Journal of Materials Processing Technology, 127, pp. 309-324 (2002).

28. Deng, W. J. et al., "Thermal stability of ultrafine grained aluminium alloy prepared by large strain extrusion machining," Materials Science and Technology, 30, pp. 850-859 (2014).

29. Knovel: Engineering Technical Reference Information, http://www.knovel.com (2008).

(Manuscript received June 24, 2016, accepted for publication January 15, 2017.) 